\title{
Spontaneous delivery or manual delivery of the placenta during caesarean: A randomized controlled trial
}

\author{
S.M. Pokharel ${ }^{1}$ \\ ${ }^{1}$ Assistant Professor of Obstetrics \& Gynecology College of Medical Sciences- Teaching Hospital, Bharatpur, Chitwan District, \\ Nepal.
}

\begin{abstract}
The study was done to compare the blood loss and the time between spontaneous delivery and manual removal of the placenta during caesarean section. We prospectively randomized and compared outcomes of 100 gravid women with manual $(n=50)$ and spontaneous $(n=50)$ placental delivery at caesarean section. Blood loss was measured after placental deliverey at caesarean and was greater in the manually delivered group $(100.9 \pm 22.5 \mathrm{ml})$ than in the spontaneous delivery group. $(55.11 \pm 21.07 \mathrm{ml}) \mathrm{P}<0.001$. The mean interval during the delivery of the newborn and the placenta is longer in spontaneous delivery group (62.02 vs. 50.5 seconds), but the mean duration of the operation was similar. Spontaneous delivery of the placenta as compared to manual expression significantly reduces the blood loss without increasing the operating time.
\end{abstract}

Key words: Placenta delivery, spontaneous, manual.

\section{Introduction}

Obstetric hemorrhage continues to be an important cause of maternal morbidity and mortality. One of the most complicating situation is in caesarean section hemorrhage. At term gravid uterus is perfused at a rate of $500-750 \mathrm{ml} / \mathrm{min}$. This physiologic hyperperfusion results in blood loss at caesarean delivery with an average of approximately $1000 \mathrm{ml}$.

Studies of on blood loss at caesarean delivery depending on the method of placental delivery have not been reported. In textbooks of operative obstetrics placental delivery is defined as a manual

Correspondence: S.M. Pokharel

E-mail: sunilmani@hotmail.com shearing of placenta from its attachment at the deciduas basalis after delivery of the fetus.

There are two main methods for placental delivery during caesarean section. Some experts manually separate the placenta from the decidua basalis and remove it from the uterus. While others prefer to wait for the spontaneous delivery. We, the obstetrician should make effort to minimize the blood loss at the time of caesarean section. When we choose any one of the methods, we have to weigh the merits and the demerits of both. In the present study we observe both types of placental separation with regard to the blood loss and the time taken for the separation of the placenta. 


\section{Materials and methods}

A prospective study was carried out in the Department of OBS \& GYNAE, College of Medical Sciences-Teaching Hospital, Bharatpur, Nepal. 100 patients undergoing caesarean section for various indication where selected randomly for the study.

Group I: spontaneous separation of the placenta. Group II: manual removal of the placenta.

Each patient was subjected to thorough history and examination. USG, BT, CT, HB (SAHLIS Method) were done. The exclusion criteria were gestational age >34 weeks, multiple pregnancy, polyhydraminos, placenta praevia, abruptio placenta, $\mathrm{PIH}$, pre eclampsia, eclampsia, premature rupture of the membrane, previous caesarean section, pregnancy with myoma, severe medical and surgical complications involving heart, kidney, brain diseases, severe anemia and bleeding disorders.

After delivery of the baby, uterine incision was secured with green armtage forceps. The time of the delivery of the baby was noted. Uterine cavity was packed with 1-2 dry sponges (pre weighed with a kidney tray) around the placenta to soak the blood. During the separation of the placenta, the time of the delivery of the placenta was noted.

Inpatient allocated for spontaneous separation of the placenta (group I) control cord traction was used to deliver the placenta. Inpatient allocated for manual removal (group II) placenta was delivered manually after delivery of the baby.

All soaked sponges were weighed in grams and the blood loss was measured in ML.

$$
\text { Blood loss }=\frac{\text { weiht of soaked sponges with kidney }- \text { weight of dry sponges with kidney tray }}{1.05}
$$

Charles et al ${ }^{1}$ (1992) measured blood loss by volume and gravimetric assessment. Means were reported with their standard deviation for continuous variation. Statistical significance was tested with using the $\mathrm{T}$ test.

\section{Results}

Demographic characteristics of all patients are comparatively presented in table I. Parity and ethnicity was not significantly different in this study. No difference existed in the group for indication for caesarean delivery. 
S.M. Pokharel et al. Spontaneous delivery or manual delivery of the placenta during caesarean.

Table 1

\begin{tabular}{lcc}
\hline & SPONTANEOUS N=50 & MANUAL N=50 \\
\hline Maternal age (years) & $24.6(3.83)$ & $23.4(3.25)$ \\
Gestational age (weeks) & $38.9(1.51)$ & $38.9(1.07)$ \\
Pre operative Hb level(gm/dl $\}$ & $1.1(0.829)$ & $10.07(0.829)$ \\
Indication for caeserean & & \\
Fetal distress & $28\{56)$ & $20\{40)$ \\
Breech & $12(24)$ & $8(16)$ \\
Contracted pelvis & $4(8)$ & $4(8)$ \\
Precious baby & $2(4)$ & $2(4)$ \\
Intra uterine growth retardation & $1(2)$ & $6(12)$ \\
Cephalo pelvic disproportion & $1(2)$ & $2(4)$ \\
Elderly primi & $1(2)$ & $1(2)$ \\
Bad obs history & $1(2)$ & $7(14)$ \\
Region & & $8(16)$ \\
Rural & $8(16)$ & $42(84\}$ \\
Urban & $42(84)$ & \\
\hline
\end{tabular}

Table 2: Shows primary outcome.

\begin{tabular}{lcccc}
\hline & Spontaneous & Manual & P value & Significance \\
\hline Mean hemoglobin (gm/dl) & & & & \\
Before surgery & $10.10 \pm 0.829$ & $10.07 \pm 0.829$ & $>0.05$ & Not significant \\
After 48 hours of surgery & $9.43 \pm 0.917$ & $8.76 \pm 0.917$ & $<0.001$ & Highly significant \\
Difference & 0.67 & 1.31 & & \\
P value & $\mathrm{P}<0.001$ & $\mathrm{P}<0.001$ & & Highly significant \\
Mean blood loss(ml) & $55.11 \pm 21.07$ & $100.9 \pm 22.52$ & $<0.001$ & Highly significant \\
Mean time taken for & & & & \\
placental delivery (sec.) & $60.02 \pm 21.68$ & $50.5 \pm 20.5$ & & \\
\hline
\end{tabular}


Journal of College of Medical Sciences-Nepal,2011, Vol-7,No-2

Table 3: Time taken for placental delivery.

\begin{tabular}{lcccc}
\hline $\begin{array}{l}\text { Time taken for placental } \\
\text { delivery (in seconds) }\end{array}$ & No. & \% & No. & Manual \\
\hline $0-20$ & 1 & 2 & 2 & 4 \\
$20-40$ & 5 & 10 & 16 & 32 \\
$40-50$ & 10 & 20 & 16 & 32 \\
$50-60$ & 16 & 32 & 4 & 8 \\
$60-80$ & 12 & 24 & 6 & 12 \\
$80-100$ & 3 & 6 & 6 & 12 \\
$100-120$ & 2 & 4 & 0 & 0 \\
$120-140$ & 1 & 2 & 0 & 0 \\
Total & $\mathbf{5 0}$ & $\mathbf{1 0 0}$ & $\mathbf{5 0}$ & $\mathbf{1 0 0}$ \\
\hline
\end{tabular}

Table 4: Blood loss in placental delivery.

\begin{tabular}{lcccc}
\hline \multirow{2}{*}{ Blood loss(m) } & \multicolumn{2}{c}{ Spontaneous } & \multicolumn{2}{c}{ Manual } \\
& No. & \% & No. & \% \\
\hline $20-40$ & 12 & 24 & 1 & 2 \\
$40-60$ & 26 & 52 & 3 & 6 \\
$60-80$ & 5 & 10 & 7 & 14 \\
$80-100$ & 5 & 10 & 10 & 20 \\
$100-120$ & 2 & 4 & 24 & 48 \\
$120-140$ & 0 & 0 & 5 & 10 \\
Total & $\mathbf{5 0}$ & $\mathbf{1 0 0}$ & $\mathbf{5 0}$ & $\mathbf{1 0 0}$ \\
\hline
\end{tabular}

Table 5: Difference in hemoglobin before and after surgery (in spontaneous and manual group).

\begin{tabular}{lcccc}
\hline $\begin{array}{l}\text { Difference in } \\
\text { hemoglobin (g/dl) }\end{array}$ & \multicolumn{2}{c}{$\begin{array}{c}\text { Spontaneous } \\
\text { (Group I) }\end{array}$} & \multicolumn{2}{c}{ Manual } \\
(Group II) & No. & \% \\
\hline $0-0.4$ & No. & \% & 2 & 4 \\
$0.4-0.8$ & 26 & 52 & 7 & 14 \\
$0.8-1.2$ & 12 & 24 & 11 & 22 \\
$1.2-1.6$ & 5 & 10 & 22 & 44 \\
$1.6-2$ & 4 & 8 & 8 & 16 \\
Total & 3 & 6 & $\mathbf{5 0}$ & $\mathbf{1 0 0}$ \\
\hline
\end{tabular}


S.M. Pokharel et al. Spontaneous delivery or manual delivery of the placenta during caesarean

\section{Discussion}

Blood loss was significantly greater in the manually delivered placenta group than in the spontaneously delivered placenta group $(\mathrm{P}<0.001)$ (Table 4).

Maximum number of patients $24(48 \%)$ in group II (manual) lost between 100-120ml of blood. Maximum blood loss was seen in $5(10 \%)$ patients which was around 120-140ml. In comparison to this, maximum patients $26(52 \%)$ in group I (spontaneous) lost between $40-60 \mathrm{ml}$ of blood. Maximum blood loss $100-120 \mathrm{ml}$ in this group was seen only in $2(4 \%)$ cases.

Nine patients of manual group and two patients of spontaneous group required one unit of blood transfusion.

Gol et $\mathrm{al}^{2}$ concluded that manual delivery of the placenta is not associated with a significantly greater risk of operative blood loss compared with spontaneous placental separation.

Mc curdy et al ${ }^{1}$, Wilkinson ${ }^{3}$, Morales et $\mathrm{al}^{4}$, Dehbashi ${ }^{5}$ concluded in their study that the blood loss measured at cesarean delivery was greater in manually delivered group than in the spontaneous delivered group. The decrease in postoperative $\mathrm{Hb}$ was significantly greater in the manual removal group than in the spontaneous expulsion group after $48 \mathrm{hrs}$ (table 5).

Most of the patients 26 (52 \%) in group I had minimal difference of $0-0.04$ grams / $\mathrm{dl}$ in $\mathrm{Hb} 48$ after 48 hrs of surgery; whereas maximum no 22 (44\%) of patients in group II showed a difference of $1.2-1.6 \mathrm{gm} / \mathrm{dl}$ in $\mathrm{Hb}$ level after $48 \mathrm{hrs}$ of surgery.
Hidar et $\mathrm{al}^{6}$ concluded that the decrease in post operative $\mathrm{Hb}(\mathrm{p}<0.05)$ and Hematocrit $(\mathrm{p}<0.001)$ was significantly greater in manual removal group at $48 \mathrm{hrs}$ post operatively.

In this study ,a significant decrease in blood loss was seen in patients undergoing caesarean delivery with spontaneous delivery of placenta than manually. Additional support for greater blood loss in the manual placental delivery group was found with a significantly greater decrease in $\mathrm{Hb}$ concentration at after $48 \mathrm{hrs}$ of operation (1.31 vs. $0.67 \mathrm{~g} / \mathrm{dl}$ ). The duration of surgery was not altered by the mode of placental delivery.

Spontaneous separation of placenta is advocated at the time of caesarean section because reduce blood loss helps in decreasing the post operative morbidity and improves post operative recovery.

\section{Conclusion}

Spontaneous delivery of the placenta as compared to manual expression significantly reduces the blood loss without increasing the operating time. Blood loss following delivery of the placenta at the caesarean section was significantly less after the spontaneous expulsion of placenta as compared to manual expulsion .

\section{References}

1. CM McCurdy, EF Magann, CJ McCurdy et al. The effect of placental management at cesarean delivery on operative blood loss. Am J Obstet Gynaecol 1992; 167:1363-7.

2. M. Gol, A.Boaloglu, C. Aydin et al. Does manual removal of the placenta affect operative blood loss 
Journal of College of Medical Sciences-Nepal,2011,Vol-7,No-2

during cesarean section? Eur J Obstet Gynaecol 2004;

112:57-60.

3. C. Wilkinson, M.W .Enkin. Manual removal of the placenta at cesarean section. Cochrane Database Syst Rev. 2000; 2:CD000130.

4. M. Morales, G. Ceysens, N. Jastrow, et al. Spontaneous delivery or manual removal of the placenta during cesarean section: a randomized clinical trial. $B J O G$ 2004; 111:908-12.
5. S. Dehbashi, M. Honarvar, F.H. Fardi. Manual removal or spontaneous placental delivery and postcesarean endometritis and bleeding. Int J Obstet Gynaecol 2004;86:12-5.

6. S. Hidar, TM Jennane, S. Bouguizane et al. The effect of placental removal method at cesarean delivery on perioperative hemorrhage: a randomized clinical trial ISRCTN 49779257. Eur J Obstet Gynaecol Reprod Biol 2004; 112:179-82. 